\title{
New Treatments for Chronic Inflammatory Demyelinating Polyneuropathy
}

\author{
Emily K Mathey ${ }^{1}$ and John D Pollard ${ }^{2}$
}

1. Research Fellow; 2. Emeritus Professor, Brain and Mind Research Institute, University of Sydney, Australia

\begin{abstract}
Chronic inflammatory demyelinating polyneuropathy (CIDP) is the most common treatable chronic neuropathy in the western world. There are three treatment options currently available for CIDP: intravenous immunoglobulin, plasma exchange or corticosteroids. Despite the efficacy of these therapies CIDP patients are often left with permanent neurological deficits, have a poor clinical prognosis or in some cases do not respond to treatment. Furthermore, high cost and restricted availability make them unfeasible in some treatment centres, especially in the developing world. Recent advances in the understanding of the underlying pathogenic mechanisms in CIDP have brought a number of novel agents into consideration for use in CIDP. Many of these novel therapies have been used in similar autoimmune disorders and target immunopathogenic pathways common to CIDP. Here we review a number of these novel therapies and their applicability to CIDP.
\end{abstract}

\section{Keywords}

CIDP, therapy, pathogenesis, Schwann cell, autoimmune, intravenous immunoglobulin, monoclonal antibodies, node of Ranvier

Disclosure: The author has no conflicts on interest to declare.

Received: 3 April 2013 Accepted: 24 April 2013 Citation: European Neurological Review, 2013;8(1):51-6 DOl:10.17925/ENR.2013.08.01.51

Correspondence: Emily Mathey, Neuroinflammation Laboratory, Level 7, BMRI, 94 Mallet St, Camperdown, NSW, Australia, 2050. E: emily.mathey@sydney.edu.au

Chronic inflammatory demyelinating polyneuropathy (CIDP) is the most common treatable chronic neuropathy in the western world with a prevalence ranging from one to nine cases per 100,000.1 Typical onset of CIDP is between the ages of 30 and 60 years and presents as either a relapsing or progressive, symmetrical neuropathy with proximal and distal weakness which develops over at least 2 months. ${ }^{2}$ CIDP and its variants comprise group of inflammatory demyelinating diseases of the peripheral nervous system (PNS) in which the immune system mounts an aberrant attack on the nerve. Although the majority of patients can be successfully treated with current therapies there remains a considerable proportion that does not respond or are left with permanent disability. Here we review current therapies and novel approaches aimed at arresting the underlying immunopathogenic mechanisms of CIDP.

\section{Immunopathogenesis}

CIDP is assumed to be an autoimmune disease mediated by humoral and/or cellular immunity against as yet undefined Schwann cell/myelin antigens (see Figure 1). Although the trigger for the autoimmune response is unknown various infectious agents have been implicated in the process but none has been confirmed as a cause of molecular mimicry as in the case of certain subtypes of Guillain-Barre Syndromé. The autoimmune aetiology is supported by studies in both the human disease and animal models in which cell-mediated and humoral mechanisms act synergistically to cause damage to peripheral nerves.

\section{Cellular Mechanisms}

A variety of infiltrating inflammatory cells can be found in CIDP sural nerve biopsies including CD8+T cells, CD4+ T cells and macrophages. ${ }^{3,4}$ When autoreactive $T$ cells become activated in the periphery they home to the nerve, adhere to the endothelial cells of endoneurial blood vessels by interacting with adhesion molecules such as VCAM-1 and ICAM-1, roll along the vessel surface and then migrate across the blood nerve barrier (BNB). These activated $\mathrm{T}$ cells secrete an array of inflammatory mediators such as matrix metalloproteinases, ${ }^{5}$ pro-inflammatory cytokines/chemokines ${ }^{6,7}$ and many other molecules which contribute to the permeabilisation of the BNB and upregulation of the immune response within the nerve. Breakdown of the BNB is a critical event as it allows soluble factors such as antibodies access to the endoneurium and can be seen as gadolinium enhancement in MRI of CIDP patients. ${ }^{8,9}$

Macrophages are the dominant infiltrating inflammatory cell in CIDP nerve and form clusters around endoneurial vessels. ${ }^{10}$ Activated resident and recruited macrophages play an active role in many aspects of the immune response including antigen presentation, release of pro-inflammatory cytokines or toxic mediators and end stages of demyelination by stripping away and phagocytising myelin. ${ }^{11}$ In ultrastructural studies of CIDP nerve biopsies macrophages can be seen invading the Schwann cell cytoplasm and destroying the myelin or splitting the myelin by extending elongated processes between the lamellae. ${ }^{12}$

The role of CD8+ T cells in the pathogenesis is more contentious but marked upregulation of MHC class I on Schwann cells in CIDP nerve ${ }^{13}$ could enable recognition and attack by cytotoxic (CD8+) T cells. Such a mechanism occurs in leprosy when Schwann cells infected with Mycobacterium leprae are lysed by CD8+ T cells. ${ }^{14}$ To date, no foreign or autoantigen has been identified as a CD8+ cell target in CIDP but a recent study has detected clonally expanded CD8+ cells in sural nerve biopsies and peripheral blood of CIDP patients. ${ }^{15}$ These CD8+ clones were enriched in the nerve and provide some evidence that an antigen-driven, CD8+ cell mediated attack on the nerve is involved 


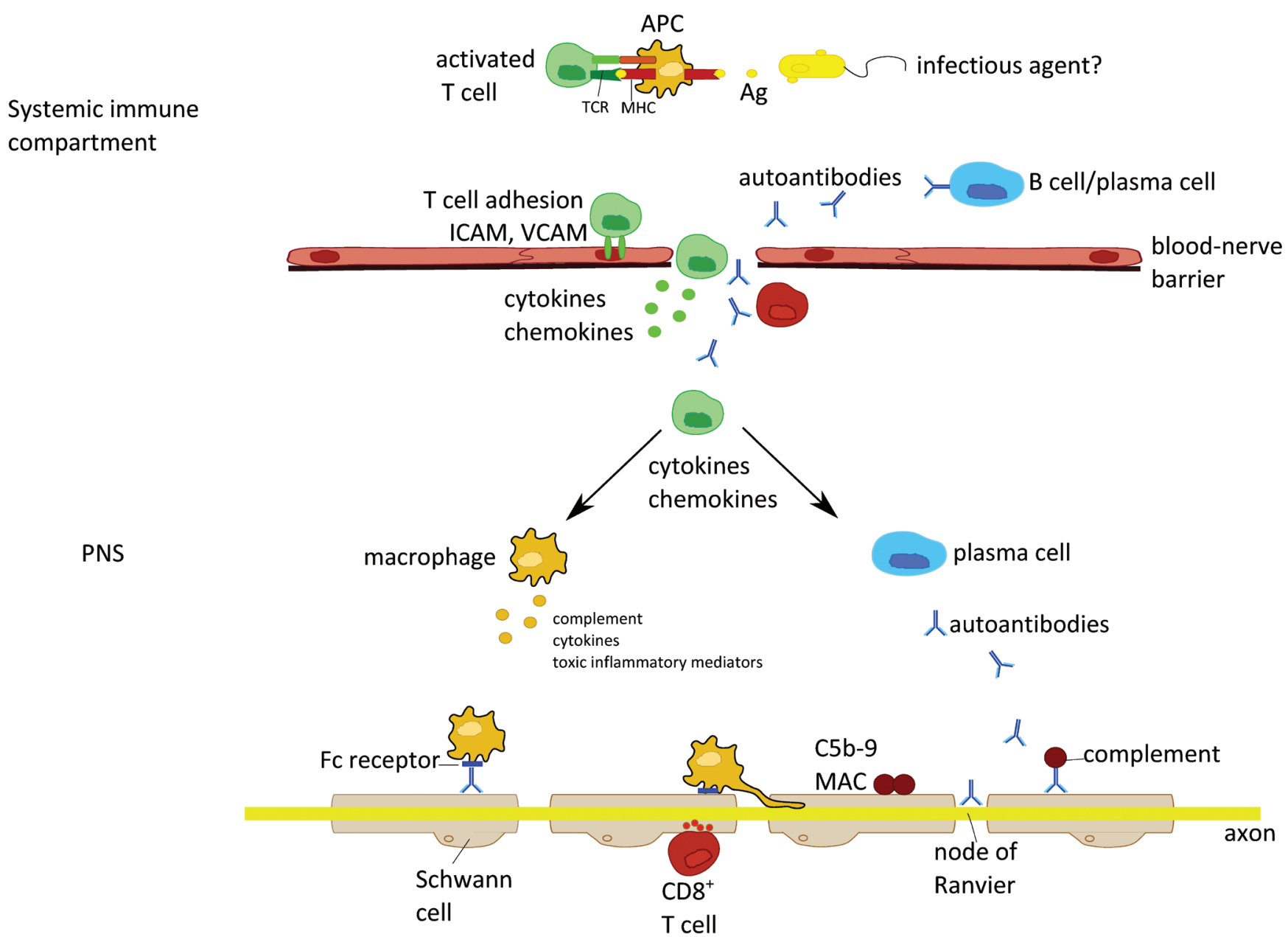

The putative antigen is presented by antigen presenting cells to autoreactive T cells in the peripheral immune compartment. These T cells become activated and undergo clonal expansion releasing numerous inflammatory mediators such as cytokines, chemokines and matrix metalloproteinases. Activated T cells cross the blood-nerve barrier (BNB) by adhering to endothelial cell adhesion molecules such as ICAM and VCAM and transmigrating into the endoneurium. The migration of $T$ cells and the release of inflammatory mediators contributes to breakdown of the BNB allowing humoral factors such as autoantibodies access to the endoneurium. Upregulation of cytokines and chemokines within the nerve leads to activation of macrophages and macrophage-mediated demyelination. B cells are also activated and secrete antibodies which bind to targets on the myelin/Schwann cell or node of Ranvier resulting in complement deposition or binding to the FC receptors on macrophages. Activation of the complement system leads to deposition of C5b-9/MAC and subsequent cell lysis. CD8+ may also contribute to tissue damage through the direct lysis of cells. Ag = antigen; ICAM = intercellular adhesion molecule; MAC = membrane attack complex; $M H C=$ major histocompatibility complex; TCR = T cell receptor; $V C A M=$ vascular cell adhesion molecule.

in the pathogenesis of CIDP. A recent analysis of the T cell repertoire in CIDP patients with and without intravenous immunoglobulin (IVIg) treatment found a broader activation of $\mathrm{CD} 8+$ than $\mathrm{CD} 4+\mathrm{T}$ cells which was reduced after treatment with IVIg. 16

There is also evidence that the immunoregulatory cellular response is impaired in CIDP patients. ${ }^{17,18}$ CD4+CD25highFoxp3+Tregs isolated from CIDP patients were less effective in suppressing proliferative responses than those from healthy controls ${ }^{17}$ which could contribute to the immune dysfunction seen in CIDP.

\section{Humoral Mechanisms}

The efficacy of plasma exchange (PE) and IVIg in the treatment of CIDP indicates that humoral mechanisms are critical to the pathogenesis of CIDP. This is supported by the ability of serum from CIDP patients to cause demyelination ${ }^{19}$ and impair nerve conduction ${ }^{19,20}$ when passively transferred into animal models. Studies have also described immunoglobulin and complement deposition on myelin and Schwann cells in sural nerve biopsies. ${ }^{21,22}$ The specific antigenic target of these antibodies is unknown but due to the striking nature of the demyelination seen in the histopathogical sections of CIDP nerve, myelin proteins located in the compact myelin have long been thought of as the most likely candidate autoantigens. Most evidence for a role of an autoimmune response to myelin proteins in CIDP is based on the similarities to experimental autoimmune neuritis (EAN), an animal model induced by immunisation with known myelin antigens. However, after many years of investigation evidence for a pathogenic role of autoantibody responses to the major myelin proteins in CIDP is inconclusive. Although some studies have detected autoantibody responses to $\mathrm{P} 2,{ }^{23} \mathrm{PO},{ }^{19,24-26}$ PMP- $22^{27}$ and connexin ${ }^{28}$ in CIDP serum, others have not. ${ }^{29}$ Even more contentious is the debate surrounding the pathogenicity of these antibodies directed towards the major myelin proteins, since only anti-P0 antibodies have been shown to be pathogenic in vivo by intraneural injection ${ }^{24,30}$ and passive transfer. ${ }^{24}$ Recent studies on autoantibody specificity are moving away from proteins located in the compact myelin towards those in the non-compact myelin and the axoglial junctions. ${ }^{31-33}$ Axoglial proteins are crucial to the formation of the node of Ranvier and paranodal regions of myelinated axons. These regions are essential for efficient saltatory conduction acting as ion diffusion barriers separating the node of Ranvier from the myelinated internodes. Indeed, in CIDP nerves nodal and paranodal regions are disrupted and the proteins vital for maintaining structural integrity are abnormally 
expressed and distributed. ${ }^{34}$ In EAN induced by immunisation with PNS myelin, the disruption of the nodal proteins neurofascin and gliomedin occurs prior to the dispersion of NaV channels and is associated with the generation of serum auto-antibodies to these molecules. ${ }^{35}$ Devaux and Yuki ${ }^{32}$ found that $30 \%$ of patients with CIDP have serum IgG that binds to either the Nodes of Ranvier or the pananodes in teased nerve fibres and in some cases identified the target antigens as neurofascin, gliomedin or contactin. Anti-neurofascin antibodies have been found in $4 \%$ of CIDP patients and anti-neurofascin monoclonal antibodies have been shown to prolong and enhance disease by passive transfer into rats with EAN. ${ }^{31,36}$ Disruption of the node of Ranvier by autoantibodies could contribute to conduction block by interfering with ion channel function and salutatory conduction which may contribute to the rapid recovery which may occur after treatment that removes antibodies from the circulation, or inactivates them. ${ }^{37}$

\section{Current Treatments for Chronic Inflammatory Demyelinating Polyneuropathy}

Three standard therapies for CIDP have shown efficacy in clinical trials: IVIg, plasma exchange and corticosteroids (see Table 1). Approximately two-thirds of patients show some clinical improvement after treatment with one of these therapies but the chosen therapy will depend upon availability, cost and patient response and the regime needs be individualised.

\section{Plasma Exchange}

Plasma exchange (PE) eliminates soluble factors such as pathogenic antibodies, circulating immune complexes, inflammatory mediators, proinflammatory cytokines and complement from the patient's circulation by taking the blood from the patient and using filtration or centrifugation to remove the plasma. The red blood cells are then re-infused with a plasma substitute which usually consists of human albumin and saline. Two double blind randomised controlled trials (RCTS) have shown that PE is beneficial in a majority of CIDP patients. ${ }^{38-40}$ Although the improvement in disability and nerve conduction after treatment with PE can be rapid, it is also short-term and patients often relapse after stopping PE. ${ }^{41}$ For stabilisation or maintenance therapy, PE may be combined with another immunosuppressive drug treatment. ${ }^{42,43} \mathrm{PE}$ is an invasive therapy and can result in adverse events related to venous access, haemorrhage and haemodynamic changes. These factors and restricted availability have relegated $\mathrm{PE}$ to second line therapy in most centres.

\section{Intravenous Immunoglobulin}

$\mathrm{IVIg}$ is used to treat a variety of disorders of the immune system and consists of pooled, polyvalent, serum IgG from tens of thousands of donors. The exact mechanisms operating in the treatment of CIDP with IVIg remain unknown but they are likely to be a combination of many factors. IVIg has numerous effects on the immune system including FC receptor blockade, modulation of Fcy receptors on effector immune cells, binding of anti-idiotypic antibodies to autoantibodies, neutralisation of complement factors and regulation of various cytokines. ${ }^{44}$ Meta-analysis of double-blind RCTs has shown that IVIg results in significant improvement of disability lasting 2-6 weeks. ${ }^{45}$ Since the benefit is relatively short lived maintenance therapy needs to be given at a frequency to be determined on an individual basis but usually between two- and four times weekly. The efficacy of IVIg was shown to be maintained over 48 weeks when following induction with $1 \mathrm{~g} / \mathrm{kg}$ over $2-4$ days, maintenance dosage of $1 \mathrm{~g} / \mathrm{kg}$ was given over $1-2$ days every three weeks. ${ }^{46}$ Although the efficacy of IVIg has been proven in several RCTs the cost of the treatment is prohibitive and this limits its availability in some developing areas.

\section{Table 1: Cochrane Reviews in the Treatment of Chronic Inflammatory Demyelinating Polyneuropathy}

\begin{tabular}{|c|c|c|c|}
\hline Study & Year & Treatment & Result \\
\hline Eftimov et al. ${ }^{96}$ & 2009 & IVIg & $\begin{array}{l}\text { Improvement of } \\
\text { disability for } 24 \text { but } \\
\text { possibly } 48 \text { weeks } \\
\text { Short-term efficacy } \\
\text { similar to that of PE } \\
\text { and oral prednisolone }\end{array}$ \\
\hline $\begin{array}{l}\text { Mehndiratta } \\
\text { and Hughes }{ }^{49}\end{array}$ & 2012 & Corticosteroids & $\begin{array}{l}\text { Efficacy of high-dose } \\
\text { monthly oral dexameth- } \\
\text { asone was not statisti- } \\
\text { cally different from that } \\
\text { of daily standard-dose } \\
\text { oral prednisolone }\end{array}$ \\
\hline $\begin{array}{l}\text { Mehndiratta } \\
\text { and Hughes }\end{array}$ & 2012 & $\begin{array}{l}\text { Plasma } \\
\text { exchange }\end{array}$ & $\begin{array}{l}\text { Short-term improve- } \\
\text { ment in disability, clinical } \\
\text { impairment, nerve } \\
\text { conduction velocity } \\
\text { but deterioration may } \\
\text { occur upon cessation } \\
\text { of treatment }\end{array}$ \\
\hline $\begin{array}{l}\text { Mahdi-Rogers } \\
\text { et al. }{ }^{98}\end{array}$ & 2012 & $\begin{array}{l}\text { Immunomodu- } \\
\text { latory treat- } \\
\text { ment other } \\
\text { than cortico- } \\
\text { steroids, Im- } \\
\text { munoglobulin } \\
\text { and plasma } \\
\text { exchange }\end{array}$ & $\begin{array}{l}\text { Not enough evidence to } \\
\text { either support or refute } \\
\text { mild/moderate benefit } \\
\text { or harm }\end{array}$ \\
\hline
\end{tabular}

\section{Corticosteroids}

Corticosteroids were the first treatment used for CIDP and despite many anecdotal reports over more than 50 years ${ }^{47}$ there is little evidence from RCTs that supports their efficacy. Meta-analysis has provided weak evidence of short-term benefit from treatment with corticosteroids ${ }^{48,49}$ and in the short term, no significant difference to IVIg was demonstrated.50 In a RCT comparing pulsed high-dose dexamethasone versus standard prednisolone ${ }^{51}$ there was no difference in remission rates after 1 year between the two regimens and long-term follow-up after a median of 4.5 years reported cure or long-term remission in $26 \%$ of patients. ${ }^{52}$ However, more than one-third of patients deteriorate ${ }^{51}$ after treatment with corticosteroids and it has been noted that patients with pure motor CIDP are more likely to respond in this manner. ${ }^{49}$ Despite the well recognised adverse effects of long term steroids, corticosteroids are relatively inexpensive and easy to administer making them extensively used in some centres for CIDP. Various regimes have been recommended for their use. Most commonly oral prednisone is given in a dose of $1-1.5 \mathrm{mg} / \mathrm{kg}$ until improvement is maintained and then the dose is tapered until the lowest effective maintenance dose is reached; ${ }^{53}$ oral dexamethasone $40 \mathrm{mg} /$ day for 4 days every month has been recommended; ;1,54 Intravenous methylprednisone $0.5-1.0 \mathrm{gm}$. Four- to five days every month ${ }^{55}$ or pulsed oral methylprednisolone..$^{56}$

\section{Immunosuppressive Therapy}

No controlled trials have been performed for immunosuppressive drugs, except for azathioprine ${ }^{57}$ and methotrexate, ${ }^{58}$ neither of which has proven efficacy. However these agents may be used with corticosteroids to reduce the need for IVIg or PE or when these are ineffective, and their use is widespread. Although there is only anecdotal evidence on which 


\section{Chronic Inflammatory Demyelinating Polyneuropathy}

to base this practise ${ }^{45}$ azathioprine is widely used in combination with low maintainence doses of corticosteroids and provides inexpensive therapy in several specialist centres. ${ }^{59,60}$ Mycophenylate mofetil is more expensive but used in a similar fashion is highly regarded by other groups. ${ }^{61,62}$ Cyclophosphamide ${ }^{63}$ and cyclosporin ${ }^{64}$ have been recommended in severe refractory cases.

\section{Novel Future Treatments}

While the efficacy of the three main treatments are widely acknowledged there remains a significant proportion of patients, around $30 \%$, for whom there is no effective treatment. ${ }^{65}$ The development of alternative therapies to treat these unresponsive patients is needed. No new treatments are recommended in the most recent European Federation of Neurological Societies/Peripheral Nerve Society CIDP management guidelines ${ }^{2}$ which are largely based on the findings of Cochrane reviews of clinical trials. However, new treatments specifically intended for the treatment of CIDP are rarely designed; instead therapies that have proved successful in other more common conditions with similar autoimmune pathogenesis such as multiple sclerosis (MS), rheumatoid arthritis (RA) or other autoimmune disorders are applied, often on a case-by-case basis when all other attempts at treatment have failed. These novel agents are used with the rationale that they can inhibit specific pathways of disease pathogenesis in CIDP outlined in Figure 1.

\section{Subcutaneous Immunoglobulin}

Subcutaneous immunoglobulin (SCIg) was developed for the treatment of those patients with primary immunodeficiency diseases who either experienced unacceptable adverse reactions to IVIg or in whom vascular access was difficult. The advantages of SCIg over IVIg include the ability for patients to administer the treatment at home via a small portable pump, fewer adverse effects and lower cost. ${ }^{66} \mathrm{~A}$ number of studies have been undertaken on the efficacy of SCIg in those CIDP patients who had previously responded to IVIg. In one such study $29 \mathrm{CIDP}$ patients who had been undergoing maintenance therapy with IVIg self-administered either SCIg at a dose corresponding to their equivalent pre-study IVIg or subcutaneous saline. ${ }^{67}$ After twice- or thrice weekly infusions over 12 weeks, treatment with the SCIG resulted in improved isokinetic muscle strength (IKS), grip strength, walking performance and disability score compared with the placebo. Side effects were limited to the injection site and $70 \%$ of the participants preferred to continue with SClg rather than revert to their previous IVIg regimen. ${ }^{67}$

\section{Monoclonal Antibodies}

The majority of humanised monoclonal antibodies that have been used to treat autoimmune diseases specifically target an individual cell subset, a particular pro-inflammatory mediator such as a cytokine or the general trafficking of immune cells by blocking adhesion molecules. Examples of these strategies are; rituximab which targets the CD20 molecule on B cells and was developed for non-Hodgkin's lymphoma, ${ }^{68}$ etanercept which targets the cytokine TNF $\alpha$ and was developed for RA ${ }^{69}$ and natalizumab which targets the adhesion molecule $\alpha 4$ integrin was developed for MS.70

\section{Rituximab}

Rituximab is an antibody directed against the CD20 molecule expressed by B cells in almost all stages of development from the pre-B cell to later stages of differentiation but is not expressed by plasma cells. It is commonly used to treat B cell lymphoma and rheumatoid arthritis and can reduce inflammatory brain lesions and clinical relapses in relapsing remitting MS.71 Rituximab use has been analysed in a retrospective, observational, multicentre study of 13 CIDP patients who were partial or non-responders to conventional therapy.72 Nine patients (seven with concurrent haematological diseases) improved clinically or maintained the improvement seen with IVIg/PE after a median time of 2 months following the course of rituximab and the effect lasted for up to 1 year. In a similar retrospective, observational, multicentre study of CIDP, 110 non-responders to conventional therapy analysed 18 patients who were treated with rituximab. ${ }^{73}$ Six of the 18 patients responded to rituximab showing at least a one point improvement on the Rankin scale. A number of case studies have reported on the efficacy of rituximab treatment in CIDP when there is a co-existent B cell disease such as idiopathic thrombocytopaenic purpura, ${ }^{74}$ SLE75 and Morvan syndrome and myasthenia gravis ${ }^{76}$ and it appears that treatment with rituximab benefits those with concomitant haematological disease more than those with idiopathic CIDP.77

\section{Natalizumab}

Natalizumab is a humanised monoclonal antibody directed against the adhesion molecule $\alpha 4$ integrin and has been approved for use in the treatment of multiple sclerosis and Crohn's disease. Binding of natalizumab to $\alpha 4$ integrin on activated T cells inhibits their adherence to the endothelium of blood vessels preventing subsequent egress from the circulation into the target tissue. To date there has been one case report describing the use of natalizumab in $\mathrm{CIDP}^{78}$ The patient treated with natalizumab showed no clinical improvement even though studies of peripheral venous $T$ cells post treatment showed binding of the natalizumab to the $\alpha 4$ integrin as expected. Given that natalizumab has been associated with the development of progressive multifocal leukoencephalopathy (PML) and must be used with stringent pharmacovigilance measures and risk management plan, ${ }^{79}$ treatment of CIDP with natalizumab is not recommended until its efficacy has been tested in controlled clinical trials. ${ }^{78}$

\section{Alemtuzumab}

Alemtuzumab is a humanised monoclonal antibody directed towards the CD52 molecule expressed on B and T cells, macrophages and monocytes. Binding of alemtuzumab to the CD52 antigen causes complement dependent cell lysis, antibody dependent cytotoxicity or apoptosis which results in a rapid and extended depletion of lymphocytes and monocytes. Alemtuzumab has been used in leukaemia and multiple sclerosis ${ }^{80,81}$ and a small number of IVIg-dependent CIDP patients reported in a retrospective study. ${ }^{82}$ Seven patients in whom immunomodulatory therapy had failed to decrease the interval between IVIg infusions were given alemtuzumab and followed for an average of 785 days. After treatment with alemtuzumab monthly IVIG use was reduced by $26 \%$ and the administration interval increased from 22 to 136 days. $^{82}$ Two patients had a long remission, two had a partial response and there was no obvious benefit in the remaining three patients. However, three patients developed autoimmune disease after treatment - a well documented side effect of alemtuzmab use.

\section{Eculizumab}

Eculizumab is a humanised monoclonal antibody directed towards the human complement factor $\mathrm{C} 5$ and has been used to treat the complement mediated lysis of red blood cells in paroxysmal nocturnal haemoglobinuria. ${ }^{83}$ Binding of eculizumab to C5 prevents terminal complement activation and the subsequent formation of the membrane attack complex and cell Iysis. Although eculizumab has not been tested in CIDP it has been used in an open-label study in multifocal motor neuropathy (MMN) patients to assess safety and tolerability in combination with IVIg. ${ }^{84}$ Treatment with eculizumab in combination with IVIg was well tolerated and safe but there 
was minimal improvement in objective clinical outcome measures in MMN. Whether eculizumab would be effective in the treatment of CIDP needs to be addressed in a clinical trial but it has been used to some effect in pre-clinical proof of principal animal studies where it can prevent anti-GQ1b antibody mediated complement dependent lysis of Schwann cells at the neuromuscular junction. ${ }^{85}$

\section{Etanercept}

Etanercept is a TNF- $\alpha$ antagonist that is commonly used to treat RA and psoriasis. In an uncontrolled, retrospective study of $10 \mathrm{CIDP}$ patients treated with etanercept three improved, three had possible improvement and two worsened after treatment. ${ }^{86}$ While etanercept may be effective in some CIDP patients it has also been associated with the development of demyelinating neuropathy in patients taking it for other conditions ${ }^{87,88}$ and exacerbations of multiple sclerosis.

\section{Fingolimod (FTY720)}

Fingolimod is a sphingosine-1-phosphate (S1P) receptor modulator that binds to S1P receptors on lymphocytes. ${ }^{89}$ Binding of fingolimod to the S1P receptor causes lymphocytes to be sequestered in the secondary lymphoid organs preventing their migration to sites of inflammation. ${ }^{90}$ Fingolimod is an oral formulation that has been approved for the treatment of RRMS where clinical trials have shown an improvement in the relapse rate, risk of disability progression and the number of inflammatory lesions on MRI ${ }^{11}$ and superior efficacy with regard to relapse rate and MRI outcomes than interferon beta1a. ${ }^{92,93}$ However, there were several serious adverse side effects reported in these clinical trials including neoplasms, herpes virus infections, first dose bradycardia and macular oedema.91-93 To date, the limited number of patients and the short duration of treatment do not allow firm conclusions about the safety profile to be made as risks can be time- and dose-dependent but fingolimod is being increasingly used in relapsing-remitting MS. Despite these caveats, fingolimod is considered a viable drug to test in CIDP warranting evaluation in a current clinical trial (EudraCT Number: 2011-005280-24). Fingolimod has also been shown to ameliorate EAN where it suppressed disease severity and duration when given at the appearance of the first neurological signs. ${ }^{94}$ The reduction in disease severity was reflected in the histopathological changes seen in the nerve where those treated with fingolimod had fewer infiltrates of T cells, B cells and macrophages and less demyelination. ${ }^{94}$

\section{Challenges Facing Future Trials for Chronic Inflammatory Demyelinating Polyneuropathy Therapies}

There are numerous agents being used or trialled in the treatment of multiple sclerosis and other diseases with similar immunopathogenic mechanisms that would be worth considering for use in CIDP. However, new therapies need to be evaluated in RCTs using objective and standardised measurements of the patient's response to treatment in terms of impairment, disability and ideally, biomarkers. Many new agents as illustrated by the monoclonal antibodies are attended by very significant adverse effects which need to be taken into account particularly since IVIg and PE are relatively safe therapies. Another difficulty is the recruitment of eligible patients for CIDP trials which has been partially addressed by the development of the CIDP disease activity status (CDAS). ${ }^{95}$ The CDAS stratifies the disease status into five categories from 'unstable active disease', 'improving', 'stable active disease' and 'remission' to 'cured'. When applied to a cohort of 106 CIDP patients $11 \%$ per cent were cured (stable and off treatment for $>5$ years), $20 \%$ were in remission (stable and off treatment for $<5$ years), $44 \%$ had stable active disease (required treatment for at least 1 year), $7 \%$ were improving after recent therapy and $18 \%$ had unstable active disease (treatment-naive or treatment-refractory). As most patients considered for inclusion in RCTs are already on therapy or have "burnt out" disease and are unlikely to respond to a new therapy the CDAS will enable a standardised classification that will exclude those patients who are cured or chronically stable and only include those with active disease. Furthermore, the percentage of patients who are either cured or in chronic remission raises the possibility that a large proportion of patients are continuing to be treated unnecessarily or being over-treated. This was seen in a RCT of add-on methotrexate versus placebo in which $44 \%$ of patients taking the placebo were able to reduce their IVIg or corticosteroid dose by more than $20 \%{ }^{58}$ by the end of the 40-week trial without deterioration.

A further challenge is the characteristic disease heterogeneity in CIDP. Despite the strict clinical and laboratory data used to categorise CIDP patients the underlying pathogenic mechanisms are likely to be many and varied. The development of biological markers which would enable CIDP patients to be categorised into subgroups for study in RCTS or predict response to therapy could ultimately make individualised and targeted treatment possible.
1. McLeod JG, Pollard JD, Macaskill P, et al., Prevalence of chronic inflammatory demyelinating polyneuropathy in New South Wales, Australia, Ann Neurol, 1999;46:910-3. Van den Bergh PY, Hadden RD, Bouche P, et al., European Federation of Neurological Societies/Peripheral Nerve Society guideline on management of chronic inflammatory demyelinating polyradiculoneuropathy: report of a joint task force of the European Federation of Neurological Societies and the Peripheral Nerve Society - first revision, Eur J Neurol, 2010;17:356-63.

Schmidt B, Toyka KV, Kiefer R, et al., Inflammatory infiltrates in sural nerve biopsies in Guillain-Barre syndrome and chronic inflammatory demyelinating neuropathy, Muscle chronic inflammatory demy
Nerve, 1996:19:474-87.

4. Cornblath DR, Griffin DE, welch D, et al., Quantitative analysis of endoneurial T-cells in human sural nerve biopsies, J Neuroimmunol, 1990;26:113-8. Leppert D, Hughes P, Huber S, et al., Matrix metalloproteinase upregulation in chronic inflammatory demyelinating polyneuropathy and nonsystemic vasculitic neuropathy, Neurology, 1999;53:62-70.

Misawa S, Kuwabara S, Mori M, et al., Serum levels of tumor necrosis factor-alpha in chronic inflammatory demyelinating polyneuropathy, Neurology, 2001:56:666-9. Hartung HP, Reiners K, Schmidt B, et al., Serum interleukin-2 concentrations in Guillain-Barre syndrome and chronic idiopathic demyelinating polyradiculoneuropathy: comparison with other neurological diseases of presumed immunopathogenesis, Ann Neurol, 1991;30:48-53.
8. Kuwabara S, Nakajima M, Matsuda S, Hattori T, Magnetic resonance imaging at the demyelinative foci in chronic inflammatory demyelinating polyneuropathy, Neurology, 1997;48:874-7.

9. Duggins AJ, MCLeod JG, Pollard JD, et al., Spinal root and plexus hypertrophy in chronic inflammatory demyelinating polyneuropathy, Brain, 1999;122(Pt 7):1383-90.

10. Sommer C, Koch S, Lammens M, et al., Macrophage clustering as a diagnostic marker in sural nerve biopsies of patients with CIDP, Neurology, 2005;65:1924-9.

11. Kiefer R, Kieseier BC, Stoll G, Hartung HP, The role of macrophages in immune-mediated damage to the peripheral nervous system, Prog Neurobiol, 2001;64:109-27.

12. Vital C, Vital A, Lagueny A, et al., Chronic inflammatory demyelinating polyneuropathy: immunopathological and ultrastructural study of peripheral nerve biopsy in 42 cases, Ultrastruct Pathol, 2000;24:363-9.

13. Pollard JD, McCombe PA, Baverstock J, et al., Class II antigen expression and $\mathrm{T}$ lymphocyte subsets in chronic inflammatory demyelinating polyneuropathy, I Neuroimmunol, 1986;13:123-34.

14. Steinhoff U, Kaufmann SH, Specific lysis by CD8+ T cells of Schwann cells expressing Mycobacterium leprae antigens, Eur I Immunol, 1988;18:969-72.

15. Schneider-Hohendorf T, Schwab N, Uceyler N, et al., CD8+ T-cell immunity in chronic inflammatory CD8+ T-cell immunity in chronic inflammatory
demyelinating polyradiculoneuropathy, Neurology, 2012;78:402-8.
16. Mausberg AK, Dorok M, Stettner M, et al., Recovery of the T-cell repertoire in CIDP by IV immunoglobulins, Neurology, 2013;80:296-303.

17. Sanvito L, Makowska A, Gregson N, et al., Circulating subsets and CD4(+)CD25(+) regulatory T cell function in chronic inflammatory demyelinating polyradiculoneuropathy, Autoimmunity, 2009;42:667-77.

18. Chi $\mathrm{L}$, Wang $\mathrm{HB}$, Wang WZ, Impairment of circulating $\mathrm{CD} 4+\mathrm{CD} 25+$ regulatory $\mathrm{T}$ cells in patients with chronic CD4+CD25+ resulatinating polyradicus with chronic inflammatory demyelinating polyradiculoneuropath Peripher Nerv Syst, 2008;13:54-63.

19. Yan WX, Taylor J, ndrias-Kauba S, Pollard JD, Passive transfer of demyelination by serum or IgG from chronic inflammatory demyelinating polyneuropathy patients, Ann Neurol, 2000;47:765-75.

20. Heininger K, Liebert UG, Toyka KV, et al., Chronic inflammatory polyneuropathy. Reduction of nerve conduction velocities in monkeys by systemic passive transfer of immunoglobulin G, J Neurol SCi, 1984;66:1-14. Dalakas MC, Engel WK, Immunoglobulin and complement deposits in nerves of patients with chronic relapsing polyneuropathy, Arch Neurol, 1980;37:637-40. Hays AP, Lee SS, Latov N, Immune reactive C3d on the surface of myelin sheaths in neuropathy, I Neuroimmunol, 1988;18:231-44.

23. Inglis HR, Csurhes PA, McCombe PA, Antibody responses to peptides of peripheral nerve myelin proteins $\mathrm{PO}$ and $\mathrm{P} 2$ in patients with inflammatory demyelinating neuropathy, J Neurol Neurosurg Psychiatry, 2007;78:419-22. 


\section{Chronic Inflammatory Demyelinating Polyneuropathy}

24. Yan WX, Archelos JJ, Hartung HP, Pollard JD, PO protein is a target antigen in chronic inflammatory demyelinating polyradiculoneuropathy, Ann Neurol, 2001;50:286-92.

25. Khalili-Shirazi A, Atkinson P, Gregson N, Hughes RA Antibody responses to $\mathrm{PO}$ and $\mathrm{P} 2$ myelin proteins in Guillain-Barre syndrome and chronic idiopathic demyelinating polyradiculoneuropathy, I Neuroimmuno 1993:46:245-51.

26. Allen D, Giannopoulos K, Gray I, et al., Antibodies to peripheral nerve myelin proteins in chronic inflammator demyelinating polyradiculoneuropathy, J Peripher Nerv Syst, 2005;10:174-80

27. Gabriel CM, Gregson NA, Hughes RA, Anti-PMP22 antibodies in patients with inflammatory neuropathy, I Neuroimmunol, 2000;104:139-46.

28. Kwa MS, van $\mathrm{S}, \mathrm{I}, \mathrm{Brand} \mathrm{A}$, Baas F, Vermeulen $\mathrm{M}$, Investigation of serum response to PMP22, connexin 32 and $\mathrm{P}(0)$ in inflammatory neuropathies, J Neuroimmunol 2001;116:220-5.

29. Sanvito L, Makowska A, Mahdi-Rogers M, et al Humoral and cellular immune responses to myelin protein peptides in chronic inflammatory demyelinating polyradiculoneuropathy, I Neurol Neurosurg Psychiatry, 2009;80:333-8.

30. Hughes RA, Powell HC, Braheny SL, Brostoff S, Endoneurial injection of antisera to myelin antigens, Muscle Nerve, 1985;8:516-22.

31. Ng JK, Malotka J, Kawakami N, et al., Neurofascin as a target for autoantibodies in peripheral neuropathies, Neurology, 2012;79:2241-8.

32. Devaux JJ, Odaka M, Yuki N, Nodal proteins are target antigens in Guillain-Barré syndrome, J Peripher Nerv syst, 2012;17:62-71.

33. Devaux JJ, Antibodies to gliomedin cause peripheral demyelinating neuropathy and the dismantling of the nodes of Ranvier, Am J Pathol, 2012:181:1402-13.

34. Cifuentes-Diaz C, Dubourg O, Irinopoulou T, et al., Nodes of ranvier and paranodes in chronic acquired neuropathies, PLOS One, 2011;6:e14533.

35. Lonigro A, Devaux JJ, Disruption of neurofascin and gliomedin at nodes of Ranvier precedes demyelination in experimental allergic neuritis, Brain, 2009;132:260-73.

36. Mathey EK, Yan W, Yuki N, et al., Neurofascin As A Target Antigen in Peripheral Demyelinating Neuropathies, J Peripher Nerv Syst, 2011;16:S84.

37. Pollard JD, Armati PJ, CIDP - the relevance of recent advances in Schwann cell/axonal neurobiology, J Peripher Nerv Syst, 2011;16:15-23.

38. Dyck PJ, Daube J, O'Brien P, et al., Plasma exchange in chronic inflammatory demyelinating polyradiculoneuropathy, N Eng/ I Med, 1986:314:461-5. Hahn AF, Bolton CF, Pillay N, et al., Plasma-exchange therapy in chronic inflammatory demyelinating polyneuropathy. A double-blind, sham-controlled, polyneuropathy. A double-blind, sham-controlled,
cross-over study, Brain, 1996;119(Pt 4):1055-66. cross-over study, Brain, 1996;119(Pt 4):1055-66.
Mehndiratta MM, Hughes RA, Agarwal P, Plasma Mehndiratta MM, Hughes RA, Agarwal P, Plasma polyradiculoneuropathy, Cochrane Database Syst Rev 2004; CD003906

41. Hahn AF, Bolton CF, Pillay $N$, et al., Plasma-exchange therapy in chronic inflammatory demyelinating polyneuropathy. A double-blind, sham-controlled, crossover study, Brain, 1996;119(Pt 4):1055-66.

42. Choudhary PP, Hughes RA, Long-term treatment of chronic inflammatory demyelinating polyradiculoneuropathy with plasma exchange or intravenous immunoglobulin, QJM, 1995:88:493-502.

43. Mathey EK, Pollard JD, Chronic inflammatory demyelinating polyneuropathy, I Neurol SCi, 2012

44. Lehmann $\mathrm{HC}$, Hartung HP, Plasma exchange and intravenous immunoglobulins: mechanism of action in immune-mediated neuropathies, J Neuroimmunol, 2011;231:61-9.

45. Van den Bergh PY, Hadden RD, Bouche P, et al., European Federation of Neurological Societies/Peripheral Nerve Society guideline on management of chronic inflammatory demyelinating polyradiculoneuropathy: report of a joint task force of the European Federation of Neurological Societies and the Peripheral Nerve Society - first revision Eur J Neurol, 2010;17:356-63.

46. Hughes RA, Donofrio P, Bril V, et al., Intravenous immune globulin ( $10 \%$ caprylate-chromatography purified) for globulin ( $10 \%$ caprylate-chromatography purified) for
the treatment of chronic inflammatory demyelinating polyradiculoneuropathy (ICE study): a randomised placebocontrolled trial, Lancet Neurol, 2008;7:136-44.

47. AUSTIN JH, Recurrent polyneuropathies and their corticosteroid treatment; with five-year observations of a placebo-controlled case treated with corticotrophin cortisone, and prednisone, Brain, 1958;81:157-92.

48. Mehndiratta MM, Hughes RA, Corticosteroids for chronic inflammatory demyelinating polyradiculoneuropathy, Cochrane Database Syst Rev, 2002;CD002062.
49. Hughes RA, Mehndiratta MM, Corticosteroids for chronic inflammatory demyelinating polyradiculoneuropathy, Cochrane Database Syst Rev, 2012;8:CD002062.

50. Hughes RA, Chronic inflammatory demyelinating polyradiculoneuropathy, Ann Neurol, 2001:50:281-2.

51. van Schaik IN, Eftimov F, van Doorn PA, et al., Pulsed high-dose dexamethasone versus standard prednisolone treatment for chronic inflammatory demyelinating polyradiculoneuropathy (PREDICT study): a double-blind, randomised, controlled trial, Lancet Neurol, 2010;9:245-53.

52. Eftimov $F$, Vermeulen $M$, van Doorn $P A$, et al., Long-term remission of CIDP after pulsed dexamethasone or short-term prednisolone treatment, Neurology, 2012;78:1079-84

53. Kissel JT, The treatment of chronic inflammatory demyelinating polyradiculoneuropathy, Semin Neurol 2003;23:169-80

54. Molenaar DS, van Doorn PA, Vermeulen M, Pulsed high dose dexamethasone treatment in chronic inflammatory demyelinating polyneuropathy: a pilot study, J Neurol Neurosurg Psychiatry, 1997:62:388-90.

55. Koski CL, Therapy of CIDP and related immune-mediated neuropathies, Neurology, 2002;59:S22-S7.

56. Muley SA, Kelkar P, Parry GJ, Treatment of chronic inflammatory demyelinating polyneuropathy with pulsed oral steroids, Arch Neurol, 2008;65:1460-

57. Dyck PJ, O'Brien P, Swanson C, et al., Combined azathioprine and prednisone in chronic inflammatorydemyelinating polyneuropathy, Neurology, 1985;35:1173-6.

58. Randomised controlled trial of methotrexate for chronic inflammatory demyelinating polyradiculoneuropathy (RMC trial): a pilot, multicentre study, Lancet Neurol, 2009;8:158-64.

59. Yuill GM, Swinburn WR, Liversedge LA, Treatment of polyneuropathy with azathioprine, Lancet 1970:2:854-56

60. Dyck PJ, O'Brien P, Swanson C, et al., Combined azathioprine and prednisone in chronic inflammatorydemyelinating polyneuropathy, Neurology, 1985;35:1173-6.

61. Gorson KC, Amato AA, Ropper AH, Efficacy of mycophenolate mofetil in patients with chronic immune demyelinating polyneuropathy, Neurology, 2004;63:715-7.

62. Radziwill AJ, Schweikert K, Kuntzer T, et al., Mycophenolate mofetil for chronic inflammatory demyelinating polyradiculoneuropathy: An open-label study, Eur Neurol, 2006:56:37-8.

63. Gladstone DE, Prestrud AA, Brannagan TH, III, High-dose cyclophosphamide results in long-term disease remission with restoration of a normal quality of life in patients with severe refractory chronic inflammatory demyelinating polyneuropathy, I Peripher Nerv Syst, 2005;10:11-6.

64. Barnett MH, Pollard JD, Davies L, McLeod JG, Cyclosporin $A$ in resistant chronic inflammatory demyelinating polyradiculoneuropathy, Muscle Nerve, 1998;21:454-60

65. Dalakas MC, Clinical trials in CIDP and chronic autoimmune demyelinating polyneuropathies, J Peripher Nerv Syst, 2012;17(Suppl. 2):34-9.

66. Lee DH, Linker RA, Paulus W, et al., Subcutaneous immunoglobulin infusion: a new therapeutic option in chronic inflammatory demyelinating polyneuropathy, Muscle Nerve, 2008;37:406-9.

67. Markvardsen LH, Debost JC, Harbo T, et al., Subcutaneous immunoglobulin in responders to intravenous therapy with chronic inflammatory demyelinating polyradiculoneuropathy, Eur I Neurol, 2013.

68. Anderson DR, Grillo-Lopez A, Varns C, et al., Targeted anti-cancer therapy using rituximab, a chimaeric anti-CD2O antibody (IDEC-C2B8) in the treatment of non-Hodgkin's B-cell lymphoma, Biochem Soc Trans, 1997;25:705-8.

69. Feldman M, Taylor P, Paleolog E, et al., Anti-TNF alpha therapy is useful in rheumatoid arthritis and Crohn's disease: analysis of the mechanism of action predicts utility in other diseases, Transplant Proc, 1998;30:4126-7.

70. Sheremata WA, Vollmer TL, Stone LA, et al., A safety and pharmacokinetic study of intravenous natalizumab in patients with MS, Neurology, 1999;52:1072-4.

71. Hauser SL, Waubant E, Arnold DL, et al., B-cell depletion with rituximab in relapsing-remitting multiple sclerosis, N Eng/ J Med, 2008:358:676-88.

72. Benedetti L, Briani C, Franciotta D, et al., Rituximab in patients with chronic inflammatory demyelinating polyradiculoneuropathy: a report of 13 cases and review of the literature, I Neurol Neurosurg Psychiatry, 2011;82:306-8.

73. Cocito D, Grimaldi S, Paolasso I, et al., Immunosuppressive treatment in refractory chronic inflammatory demyelinating polyradiculoneuropathy. A nationwide retrospective analysis, Eur J Neurol, 2011;18:1417-21.

74. Benedetti L, Franciotta D, Beronio A, et al., Rituximab efficacy in CIDP associated with idiopathic thrombocytopenic purpura, Muscle Nerve 2008;38:1076-7.

75. Sanz PG, Garcia Mendez CV, Cueto AL, et al., Chronic inflammatory demyelinating polyradiculoneuropathy in a patient with systemic lupus erythematosus and good outcome with rituximab treatment, Rheumatol Int, 2012;32:4061-3.

76. Sadnicka A, Reilly MM, Mummery C, et al., Rituximab in the treatment of three coexistent neurological autoimmune diseases: chronic inflammatory demyelinating polyradiculoneuropathy, Morvan syndrome and myasthenia gravis, J Neurol Neurosurg Psychiatry, 2011;82:230-2. Benedetti L, Briani C, Franciotta D, et al., Rituximab in patients with chronic inflammatory demyelinating polyradiculoneuropathy: a report of 13 cases and review of the literature, I Neurol Neurosurg Psychiatry, 2011;82:306-8.

78. Wolf $\mathrm{C}$, Menge $\mathrm{T}$, Stenner MP, et al., Natalizumab treatment in a patient with chronic inflammatory demyelinating polyneuropathy, Arch Neurol, 2010;67:881-3.

79. Fernandez $O$, Best practice in the use of natalizumab in multiple sclerosis, Ther Adv Neurol Disord, 2013;6:69-79

80. Cohen JA, Coles AJ, Arnold DL, et al., Alemtuzumab versus interferon beta 1a as first-line treatment for patients with relapsing-remitting multiple sclerosis: a randomised controlled phase 3 trial, Lancet, 2012;380:1819-28.

81. Coles AJ, Twyman CL, Arnold DL, et al., Alemtuzumab for patients with relapsing multiple sclerosis after diseasemodifying therapy: a randomised controlled phase 3 trial Lancet, 2012:380:1829-39.

82. Marsh EA, Hirst CL, Llewelyn JG, et al., Alemtuzumab in the treatment of IVIG-dependent chronic inflammatory demyelinating polyneuropathy, I Neurol, 2010:257:913-9.

83. Hillmen P, Young NS, Schubert J, et al., The complement inhibitor eculizumab in paroxysmal nocturnal hemoglobinuria, N Eng/ I Med, 2006;355:1233-43.

84. Fitzpatrick AM, Mann CA, Barry S, et al., An open label clinical trial of complement inhibition in multifocal motor neuropathy, J Peripher Nerv Syst, 2011;16:84-91.

85. Halstead SK, Zitman FM, Humphreys PD, et al., Eculizumab prevents anti-ganglioside antibody-mediated neuropathy in a murine model, Brain, 2008;131:1197-208.

86. Chin RL, Sherman WH, Sander HW, et al., Etanercept (Enbrel) therapy for chronic inflammatory demyelinating polyneuropathy, J Neurol Sci, 2003;210:19-21.

87. Alshekhlee A, Basiri K, Miles JD, et al., Chronic inflammatory demyelinating polyneuropathy associated with tumor necrosis factor-alpha antagonists, Muscle Nerve, 2010:41:723-27.

88. Lozeron P, Denier C, Lacroix C, Adams D, Long-term course of demyelinating neuropathies occurring during tumor necrosis factor-alpha-blocker therapy, Arch Neuro 2009:66:490-7.

89. Matloubian M, Lo CG, Cinamon G, et al., Lymphocyte egress from thymus and peripheral lymphoid organs is dependent on S1P receptor 1, Nature, 2004;427:355-60.

90. Mandala S, Hajdu R, Bergstrom J, et al., Alteration of lymphocyte trafficking by sphingosine-1-phosphate receptor agonists, Science, 2002;296:346-9.

91. Kappos L, Radue EW, O'Connor P, et al., A placebocontrolled trial of oral fingolimod in relapsing multiple sclerosis, N Engl J Med, 2010;362:387-401.

92. Cohen JA, Barkhof $F$, Comi $G$, et al., Oral fingolimod or intramuscular interferon for relapsing multiple sclerosis, N Eng/ J Med, 2010:362:402-15.

93. Khatri B, Barkhof F, Comi G, et al., Comparison of fingolimod with interferon beta-1a in relapsing-remitting multiple sclerosis: a randomised extension of the TRANSFORMS study, Lancet Neurol, 2011;10:520-9.

94. Zhang Z, Zhang ZY, Fauser U, Schluesener HJ, FTY720 ameliorates experimental autoimmune neuritis by inhibition of lymphocyte and monocyte infiltration into peripheral nerves, Exp Neurol, 2008;210:681-90.

95. Gorson KC, van Schaik IN, Merkies IS, et al., Chronic inflammatory demyelinating polyneuropathy disease activity status: recommendations for clinical research standards and use in clinical practice, J Peripher Nerv Syst, 2010:15:326-33.

96. Eftimov $\mathrm{F}$, Winer JB, Vermeulen $\mathrm{M}$, et al., Intravenous immunoglobulin for chronic inflammatory demyelinating polyradiculoneuropathy, Cochrane Database Syst Rev, 2009; (1):CD001797.

97. Mehndiratta MM, Hughes RA, Plasma exchange for chronic inflammatory demyelinating polyradiculoneuropathy, Cochrane Database Syst Rev, 2012;9:CD003906.

98. Mahdi-Rogers M, Swan AV, van Doorn PA, Hughes RA, Immunomodulatory treatment other than corticosteroids, immunoglobulin and plasma exchange for chronic inflammatory demyelinating polyradiculoneuropathy, Cochrane Database Syst Rev, 2010;CD003280. 